\title{
Pharmacologic and nonpharmacologic options for the management of HIV infection during pregnancy
}

\section{Carmen D Zorrilla Vivian Tamayo-Agrait}

Department of Obstetrics and Gynecology, University of Puerto Rico School of Medicine, Maternal Infant Studies Center (CEMI), San Juan, Puerto Rico
Correspondence: Carmen Zorrilla Professor, Obstetrics and Gynecology, University of Puerto Rico School of Medicine, Maternal Infant Studies Center, San Juan, Puerto Rico, 00936-5067

Tel +787 77। 4739

Fax +787 77| 4739

Email carmen.zorrilla@upr.edu

\author{
This article was published in the following Dove Press journal: \\ HIVIAIDS - Research and Palliative Care \\ 7 December 2009 \\ Number of times this article has been viewed
}

\begin{abstract}
Over the past decade, significant advances have been made in the treatment of HIV-1 infection using both pharmacologic and nonpharmacologic strategies to prevent mother-to-child transmission (MTCT). Optimal prevention of the MTCT of HIV requires antiretroviral drugs (ARV) during pregnancy, during labor, and to the infant. ARVs reduce viral replication, lowering maternal plasma viral load and thus the likelihood of MTCT. Postexposure prophylaxis of ARV agents in newborns protect against infection following potential exposure to maternal HIV during birth. In general, the choice of an ARV for treatment of HIV-infected women during pregnancy is complicated by the need to consider the effectiveness of the therapy for the maternal disease as well as the teratogenic or teratotoxic potential of these drugs. Clinicians managing HIV in pregnancy need to discuss the potential risks and benefits of available therapy options so that mothers can make informed decisions in choosing the best treatment regimen for themselves and for their children.
\end{abstract}

Keywords: HIV, pregnancy, acquired immunodeficiency syndrome, antiretroviral agents

\section{Introduction}

According to the World Health Organization (WHO), an estimated 15.7 million women and 2.1 million children under the age of 15 years were living with AIDS as of December 2008. ${ }^{1}$ One of the great success stories has been the influence of perinatal interventions on the reduction of mother-to-child transmission (MTCT) worldwide. This has been more evident in developed countries where interventions are more complex and effective but costly.

Without interventions, the risk of such vertical transmission of HIV has been estimated to be $15 \%$ to $35 \%$ worldwide. ${ }^{2}$ In some developing countries, for example, Botswana, Zimbabwe, and Swaziland, the HIV epidemic has reversed the gains in infant survival made prior to $1999 .{ }^{3,4}$ Attempts to eradicate perinatal transmission of the disease have led numerous national and international health agencies to institute guidelines for the management of the woman and her infant during the antepartum, intrapartum, and postpartum periods.

In contrast with general guidelines for the management of adults with HIV infection, the consensus for the management of pregnant women with HIV infection is that antiretroviral (ARV) therapy should be initiated and continued for the duration of the pregnancy regardless of viral load and CD4 cell count in order to reduce MTCT; ${ }^{5-7}$ for women who are receiving antiretroviral drugs solely for prevention of perinatal transmission, however, delaying initiation of prophylaxis until after the first trimester can be considered..$^{5}$ In developed countries, the use of highly active antiretroviral therapy 
(HAART; which includes 2 nucleoside/nucleotide reverse transcriptase inhibitors [NRTIs] with a protease inhibitor [PI]), ARV prophylaxis for the mother and fetus and then the infant, elective cesarean delivery, and infant formula rather than breastfeeding have reduced the incidence of MTCT from between $15 \%$ to $25 \%$ to less than $2 \% .{ }^{8}$ In less developed areas, simpler and more affordable ARV regimens are being offered to treatment-naïve pregnant women and their newborns; these involve combinatorial ARV approaches, where possible, or single agent treatment, most notably the use of the nonnucleoside reverse transcriptase inhibitor (NNRTI) nevirapine (NVP), where lack of resources is a limiting factor. ${ }^{9}$ The reductions in the rate of perinatal HIV transmission have been evident worldwide (including the Caribbean) due to the diverse interventions and programs supported by a variety of international funding agencies. ${ }^{10,11}$

\section{Perinatal transmission}

One major achievement in the reduction of the MTCT of HIV was the Pediatric AIDS Clinical Trials Group Protocol 076 (PACTG 076) ${ }^{12}$ regimen involving zidovudine (AZT), which in 1994 was shown to reduce the risk of MTCT by nearly $70 \%$. The implementation of PACTG 076 coupled with increased antenatal HIV counseling and rapid testing in the United States and other countries with higher level resources ${ }^{13,14}$ have substantially decreased the perinatal MTCT of HIV. In general, although the risk of MTCT is related to maternal viral load, studies have shown a continued risk of MTCT even at low maternal plasma HIV RNA levels $\left(<1000\right.$ copies/mL); ${ }^{15,16}$ in addition, the protective effect of antenatal ARV therapy increases with its complexity and duration and results in a decline in the rate of MTCT to around 3\%. ${ }^{17-19}$

Projects to prevent MTCT in resource-limited settings have focused primarily on the provision of single-dose intrapartum and neonatal ARV as alternatives to more complex regimens. The first drug to be employed was the NRTI azidothymidine (AZT; zidovudine); subsequently NVP became the preferred agent. ${ }^{12,19-21}$ The most widely adopted regimen and that initially recommended by the WHO as an 'absolute minimum,' is a single dose of NVP given to the mother at the onset of labor and then a single dose given to the infant $\leq 72$ hours postpartum. ${ }^{9}$ Owing to the potential for development of resistance, however, the WHO has since modified this guideline to recommend combination ARV treatment as the preferred regimen for the mother where there is the capacity to do so. ${ }^{22,23}$ Thus, while single agent treatments are effective in reducing MTCT, the development of affordable regimens with superior efficacy and tolerability profiles remains an urgent global priority.

\section{Antiretroviral therapy: mechanism of action}

Since high maternal viral load increases the likelihood of MTCT, one of the most effective mechanisms of action is simply the reduction of maternal HIV-1 RNA levels, which in turn lowers fetal prenatal and postnatal HIV exposure from maternal plasma, genital secretions, ${ }^{24}$ and breast milk. ${ }^{25}$

Another possible mechanism of protection is pre-exposure of the infant to ARV agents that can cross the placenta which may protect the infant from exposure to a maternal genital tract virus during passage through the birth canal. ${ }^{26}$ In addition, postexposure prophylaxis provided through drug administration to the infant after birth would protect against a cell-free or cell-associated virus that might have entered the fetal/infant system during labor through maternal-fetal transfusion during uterine contractions or by the infant swallowing genital tract secretions during passage through the birth canal.

\section{Antiretroviral therapy in pregnancy}

This section reviews the potential toxicity of drugs that may cross the placenta, potential adverse effects that may be exacerbated during pregnancy, potential short- and long-term effects on the fetus and newborn child, and dosing changes that may be required owing to natural physiologic changes during pregnancy (eg, plasma volume expansion, ${ }^{27}$ increase in the glomerular filtration rate, ${ }^{28}$ and changes in CYP1A2, CYP3A4, and CYP2D6 activity - important enzymes involved in the xenobiotic metabolism)..$^{29,30}$

\section{Placental antiretroviral drug transfer}

In mammals, the placenta separates the maternal and fetal circulation systems while ensuring fetal growth and development by transferring oxygen, carbon dioxide, nutrients, and waste products. Transplacental transfer occurs via passive diffusion, facilitated diffusion, active transport, pinocytosis, phagocytosis, and filtration. ${ }^{31}$ Of these, the most common mechanism for drug transfer is passive diffusion. Thus, the factors defining Fick's law of diffusion (eg, membrane thickness, surface area, and the concentration gradient) determine the degree of placental drug transfer. The drug properties that govern the extent of this transfer include: molecular weight, $\mathrm{pKa}$ (the $\mathrm{pH}$ at which the drug is $50 \%$ ionized), lipid solubility, and the affinity of the substance to plasma proteins. ${ }^{31}$ In general, compounds with a molecular weight of 
less than $500 \mathrm{Da}$ exhibit complete transfer across the human placenta. Nonionized compounds cross the placenta more readily than ionized compounds do and drugs with greater lipophilicity (ie, the ability of a compound to dissolve in lipids and nonpolar solvents). Since most drugs are weak acids or bases, changes in $\mathrm{pH}$ affect their ionization and, in turn, lipophilicity and membrane permeability. ${ }^{31}$

Currently, there are eight US Food and Drug Administration (FDA)-approved NRTIs: abacavir (ABC), didanosine (ddl), emtricitabine (FTC), lamivudine (3TC), stavudine (d4T), tenofovir (TDF), zalcitabine (ddC), and AZT. All have molecular weights of around $250 \mathrm{Da}$, sufficiently small enough to pass through the placenta by simple diffusion. As expected, all have been shown to cross the placenta in the human, monkey, rabbit, rat, and mouse. ${ }^{32-39}$ The four FDAapproved NNRTIs: delavirdine (DLV), efavirenz (EFV), etravirine (TMC125) and NVP have molecular weights of $553 \mathrm{Da}, 316 \mathrm{Da}, 316 \mathrm{Da}, 435 \mathrm{Da}$, and $266 \mathrm{Da}$, respectively. ${ }^{40-43}$ Transplacental transfer of EFV is strongly suspected in humans since case reports of central nervous system malformations in neonates born to women exposed to EFV have led the manufacturer to modify the "pregnancy risk" warning label on EFV. ${ }^{41,44-46}$ It has also has been reported to cause central nervous system abnormalities in infants born to cynomolgus monkeys. ${ }^{50}$ With a molecular weight of $266 \mathrm{Da}$, transplacental transfer of NVP would be expected and indeed has been confirmed in humans. ${ }^{47-49}$ With a molecular weight of 553 Da, limited transplacental diffusion of DLV would be expected to occur. Table $1^{51-64}$ lists the chemical and physical properties that govern the diffusion of compounds across the placenta of the remaining classes of HIV drugs: PIs, fusion inhibitors, entry inhibitors, and an integrase inhibitor. In addition, the $\mathrm{pKa}$ of these compounds indicates that they are weakly basic and thus slightly ionized at physiologic $\mathrm{pH}$, thus further limiting transplacental diffusion. ${ }^{51-64}$

Lipophilicity, which is measured as a partition coefficient or a distribution coefficient ratio, is one of the most important characteristics governing the transfer of drugs through cellular membranes. ${ }^{31}$ Generally, the cellular permeability of a compound is directly proportional to its lipophilicity. However, a compound with too high a partition/distribution coefficient is sequestered in the cell membrane (a lipid bilayer), thus reducing its diffusion into the cell. Therefore, highly lipophilic drugs have essentially the same problem as hydrophilic drugs; they have difficulty diffusing through multiple aqueous membrane interfaces necessary to enter the fetal circulation. The ideal partition coefficient for membrane diffusion from studies of the blood-brain barrier is between -0.2 to 1.3 ( $\log \mathrm{P}$, partition coefficient). ${ }^{62,65}$ The partition coefficients for the protease, fusion, and integrase inhibitors listed in Table 1 are all outside this range, indicating that these drugs are highly lipophilic and should be trapped within

Table I Chemical and physical properties of HIV protease, fusion, and integrase inhibitors

\begin{tabular}{|c|c|c|c|c|c|}
\hline & $\begin{array}{l}\text { Molecular } \\
\text { weight (Da) }\end{array}$ & $\begin{array}{l}\text { Partition/distribution } \\
\text { coefficients }\end{array}$ & $\mathbf{p K a}^{\prime}$ & Water solubility, pH 7.4 & $\begin{array}{l}\text { Pregnancy } \\
\text { category }^{2}\end{array}$ \\
\hline \multicolumn{6}{|l|}{ Protease inhibitors } \\
\hline Amprenavir mesylate $^{3}$ & $505^{54}$ & 3.30 or $4.20^{60}$ & NR & Low: $\sim 0.06 \mathrm{~g} / \mathrm{L}^{60}$ & $\mathrm{C}$ \\
\hline Indinavir sulfate & $712^{55}$ & $2.90^{63}$ & $5.50^{62}$ & Low: $0.07 \mathrm{~g} / \mathrm{L}^{60}$ & C \\
\hline Lopinavir & $629^{56}$ & $5.09^{62}$ & Nonionized ${ }^{62}$ & Practically insoluble ${ }^{62}$ & $\mathrm{C}$ \\
\hline Nelfinavir mesylate & $664^{57}$ & $4.00^{60}$ & $\begin{array}{l}\mathrm{pKa}_{1}=6.00^{61} \\
\mathrm{pKa}_{2}=11.10^{61}\end{array}$ & Very low $w^{61,62}$ & B \\
\hline Ritonavir & $721^{58}$ & $\begin{array}{l}5.20^{60} \\
3.99^{62}\end{array}$ & $\begin{array}{l}\mathrm{pKa}_{1}=1.76^{62} \\
\mathrm{pKa}_{2}=2.56^{62}\end{array}$ & Low: $0.005 \mathrm{~g} / \mathrm{L}^{60}$ & B \\
\hline Saquinavir mesylate & $67 I^{59}$ & $4.10^{60}$ & 7.00 or $5.50^{60}$ & Low: $0.004 \mathrm{~g} / \mathrm{L}^{60}$ & B \\
\hline \multicolumn{6}{|c|}{ Fusion/entry inhibitors } \\
\hline Enfuvirtide & $4492^{53}$ & $-0.875^{53}$ & $4.6^{64}$ & Low $^{53}$ & B \\
\hline Maraviroc & $514^{52}$ & NR & $\begin{array}{l}\mathrm{pKa}_{1}=3.30^{52} \\
\mathrm{pKa}_{2}=2.56^{52}\end{array}$ & $\mathrm{High}^{52}$ & B \\
\hline \multicolumn{6}{|l|}{ Integrase inhibitor } \\
\hline Raltegravir & $483^{51}$ & NR & NR & $\mathrm{High}^{51}$ & $\mathrm{C}$ \\
\hline
\end{tabular}

' $\mathrm{pKa}, \mathrm{pH}$ at which $50 \%$ of the agent is ionized. ${ }^{2}$ Category $\mathrm{B}$ : drugs that, in animal reproduction studies, fail to demonstrate a risk to the fetus; however, well-controlled studies of pregnant woman have not been conducted. Category C: drugs where safety in human pregnancy has not been determined; animal studies are either positive for fetal risk or have not been conducted. ${ }^{3} \mathrm{Amprenavir}$ mesylate is no longer commercially available and has been replaced with fosamprenavir calcium, a prodrug of amprenavir. Abbreviations: HIV, human immunodeficiency virus; NR, not reported. 
cellular membranes and would be expected to exhibit very limited cross-placental transfer.

The placenta also plays an important role in the synthesis of hormones, steroids, and peptides and facilitates the transfer of nutrients and other physiologic substances via specific transporters necessary for a successful pregnancy. ${ }^{66}$ The specificity of these transporters is not strictly limited to physiologic substrates. Xenobiotics (including environmental pollutants, toxins, and therapeutic and nontherapeutic agents) that bear structural similarity to physiologic substrates are also recognized by placental transporters. Thus, although placental transporters can protect the fetus from potential adverse effects of xenobiotics, they also play a crucial role in the transfer of therapeutic agents across the maternal-fetal interface. ${ }^{66,67}$

The placental transporters that carry the widest variety of xenobiotics belong to the adenosine triphosphate-binding cassette (ABC) superfamily of active membrane transporters. ${ }^{68,69}$ These include P-glycoprotein (P-gp; eg, multidrug resistant [MDR]1, ABC1), breast cancer-resistant protein (eg, ABCG2), and several members of the multidrug-resistant protein (MRP; eg, ABCC) subfamily, such as MRP1, MRP2, and MRP5 (eg, ABCC1, $\mathrm{ABCC} 2$, and $\mathrm{ABCC} 3) .{ }^{68-71}$ In the placenta, they prohibit the maternal-fetal transfer of potentially toxic compounds. ${ }^{68}$ Of these transporters, P-gp extrudes the widest range of chemically diverse substrates, hydrophobic or slightly charged with average molecular weights of approximately $800 \mathrm{Da}$ for neutral molecules. ${ }^{72-74}$ MDR1/P-gp expression in the human placenta has been demonstrated at the protein level, ${ }^{75}$ and is located at the apical surface of the syncytiotrophoblast membrane, where it transports substrate from the trophoblast into the maternal plasma and away from the fetal circulation. ${ }^{68,76}$

The substrates of P-gp include anticancer drugs (eg, vincristine, vinblastine, the anthracyclines, etoposide, taxol, and mithramycin), cytotoxic agents (eg, colchicine and emetine), and HIV PIs (eg, nelfinavir [NFV], saquinavir [SQV], indinavir, and ritonavir). ${ }^{77,78}$ Chappuy and colleagues ${ }^{79}$ confirmed that $\mathrm{P}$-gp plays a major role in limiting penetration of PIs into the fetus. This could be advantageous at early stages of embryonic and fetal development since it reduces exposure to potentially teratogenic drugs at a time when the MTCT of HIV rarely occurs. ${ }^{80}$

Preloading of the infant before birth with an effective anti-HIV drug requires choosing drugs such as AZT that cross the placenta readily. ${ }^{5,81,82}$ Placental P-gp is an important factor that limits PI penetration, making PIs unsuitable as a prophylactic agent. ${ }^{83,84}$ Interestingly, according to the product package insert, ${ }^{52}$ the fusion inhibitor maraviroc is a substrate for the with an affinity of $35 \mu \mathrm{M}(\mathrm{Ki})$ and, thus is also probably of limited use as a prophylactic to limit the MTCT of HIV. Still, these properties could allow MVC to be effective in reducing maternal HIV viral load while protecting the fetus from exposure to a drug.

\section{Nucleoside/nucleotide reverse transcriptase inhibitors}

Nucleoside/nucleotide reverse transcriptase inhibitors have a small molecular size ( $250 \mathrm{Da})$, can cross the placenta by simple diffusion, and can cause toxic damage to both mother and infant. ${ }^{85}$ The most serious side effects associated with this class of drugs are anemia and, when used in combination therapy, lactic acidosis. However, based on pregnancies documented in the Antiretroviral Pregnancy Registry (2008), ${ }^{86}$ the most frequently used nucleoside analogs - AZT, 3TC, and d4T - do not increase teratogenicity by more than 2 -fold compared to controls. Follow-up of more than 20,000 children who had received AZT prophylaxis did not show any serious adverse effects. ${ }^{87}$ An analysis of the causes of death in 223 children who died, within the first 5 years of life, ruled out drug-related causes. ${ }^{87}$ In contrast, in a prospective study of 2644 children without infection who had been exposed to HAART, ${ }^{88}$ neurologic symptoms with persistent mitochondrial dysfunction were reported in $0.26 \%$ versus $0.01 \%$ in the general population. Nonspecific changes in cerebral magnetic resonance imaging scans in children perinatally exposed to AZT (plus 3TC) ${ }^{89}$ have been interpreted as a sign of neurotoxicity. Twenty-four weeks after combined nucleoside exposure, raised lactate values as well as impairment of hematopoiesis were noted in children. ${ }^{90}$ Mitochondriopathies have been observed at least twice in pregnant women taking a combination of $\mathrm{d} 4 \mathrm{~T} / \mathrm{ddI}$ plus NFV or NVP. ${ }^{91}$ For these reasons, the combination $\mathrm{d} 4 \mathrm{~T} / \mathrm{ddI}$ therapy is not recommended for use in pregnancy. ${ }^{5}$ Hepatic toxicity with hyperbilirubinemia was described in one pregnant woman who died of sudden acute liver failure following the administration of AZT/3TC/NFV. ${ }^{92}$

There is some concern about the effect of administering NRTIs, particularly AZT, during pregnancy. Lower levels of mitochondrial DNA have been found in the placenta and cord blood of HIV-infected women receiving AZT during their pregnancy compared to uninfected women. ${ }^{93}$ In another study, infants born to HIV-infected women exposed to AZT during their pregnancy had lower levels of mitochondrial DNA in their peripheral blood leukocytes at one and two 
years of age than those born to HIV-infected women who were not exposed to AZT; both had lower levels compared to infants born to uninfected women. ${ }^{94}$ Preclinical studies in monkeys showed that offspring receiving perinatal (in utero and for six weeks after birth) exposure to AZT alone as well as double-NRTI combinations (AZT/3TC, AZT/ddI, or d4T/3TC) had skeletal muscle mitochondrial DNA depletion and other abnormalities that persisted for 1 year compared to offspring of monkeys not receiving perinatal drug exposure..$^{95}$ The long-term relevance of these findings is not known. Nevertheless, AZT is an important component of the combination therapies used to reduce MTCT.

In animal experiments, tenofovir was not found to have any maternal toxicity but fetal growth was lowered by $13 \%$ versus controls and was associated with a slight decrease in bone density. ${ }^{96}$ Subsequently, it has been found that long-term use in adults may induce renal toxicity and osteomalacia in some patients. ${ }^{97}$ In studies of TDF-containing regimens in pediatric patients, loss in bone mineral density was observed ${ }^{98}$ but renal toxicity was not reported; 99 in a third study, renal toxicity was seen in a small number of children ${ }^{100}$ Studies of the use of TDF in regimens to reduce $\mathrm{MTCT}^{101,102}$ have suggested that it may be helpful in preventing induction of resistance to NVP (reviewed by Foster and colleagues). ${ }^{103}$ Currently, the US PHS Perinatal Guidelines recommend use of TDF as a component of combination regimens in pregnancy in the context of coinfection with hepatitis B virus, but otherwise only after consideration of other alternatives. ${ }^{5}$

\section{Nonnucleoside/nucleotide reverse transcriptase inhibitors}

Nonnucleoside/nucleotide reverse transcriptase inhibitors block reverse transcriptase by binding at a different site on the enzyme than NRTIs. ${ }^{104}$ The molecular sizes are similar to those of NRTIs and thus are expected to readily diffuse across the placenta. In the prevention of MTCT, NVP has been employed successfully, particularly in combination with AZT or 3TC. ${ }^{105,106}$ However, owing to the enhanced risk of liver toxicity during the first 18 weeks of treatment in women with CD4+ T-cell counts of more than $250 / \mu \mathrm{L}$, patients must be monitored closely, especially during dose escalation. ${ }^{5}$ Treatment with NVP in pregnant women is only recommended following very careful assessment of the benefit:risk ratio. ${ }^{5}$ Perinatal single- and 2-dose prophylaxis has resulted in the development of drug resistance. ${ }^{107,108}$ If a mother gives birth less than 2 hours following the administration of NVP or has not received any prior NVP, the newborn should receive a dose immediately after birth and another dose after 48 to 72 hours. ${ }^{47,109,110}$ Data indicate that there may be clinically significant levels of NVP in plasma for more than two weeks after stopping chronic therapy as well as after a single dose of NVP. ${ }^{111}$ Resistance mutations have been identified postpartum in women who received single-dose intrapartum NVP prophylaxis as well as in women who had stopped NVP-containing combination regimens taken during pregnancy for the prevention of MTCT. ${ }^{112,113}$ In the latter study, ${ }^{113}$ NVP resistance was seen in $13 \%$ of women despite the staggered discontinuance of ARV drugs (in which the nucleoside backbone was continued for five days after stopping NVP). Furthermore, in the Perinatal HIV Prevention Trial, women who received a single dose of NVP intrapartum were less likely to achieve virologic suppression at six months, compared with women not receiving intrapartum NVP, suggesting that their responses to subsequent NNRTI therapy were compromized; those that had NVP resistance mutations had an even poorer response. ${ }^{114}$ Preliminary data from a South African study ${ }^{115}$ suggest that administration of a single dose of NVP combined with AZT/3TC and given intrapartum and then for three or seven days postpartum, may reduce the development of resistance compared with the administration of single-dose NVP.

To our knowledge, there are no published studies reporting on the use (either pharmacokinetics or efficacy) of etravirine (TMC125), a recently approved drug, during pregnancy. Efavirenz has been reported to cause embryonic toxicity in rhesus monkeys and neural tube defects in humans after first trimester exposure. ${ }^{45,86,116}$ Thus, EFV is not used during the first trimester and is used only after the second trimester when there is no alternative treatment option and provided that reliable contraception is then practiced after delivery. ${ }^{5}$

\section{Protease inhibitors}

Protease inhibitors prevent HIV replication by inhibiting the activity of HIV-1 protease, an enzyme used by the viruses to cleave nascent proteins for final assembly of new virions. ${ }^{117}$ The transplacental diffusion of agents of this class is partly limi ted by their molecular weight (Table 1) but most importantly by their affinity for the placental P-gp transporter. ${ }^{77,79}$ The use of PIs in combination therapy has been suspected to contribute to increased rates of premature births and malformations. ${ }^{118}$ However, this is unlikely owing to the minimal placental transfer of PIs, ${ }^{119}$ and any link has not been confirmed by other studies. ${ }^{120,121}$ Increases in the incidence of premature births were reported by Thorne and colleagues ${ }^{122}$ whereas no increases were reported by Mandelbrot and colleagues ${ }^{18}$ 
or Tuomala and colleagues. ${ }^{120,121}$ In addition, in a study of 233 pregnancies, multiple regression analysis revealed no association between prematurity rate and the individual PIs used or the week of gestation that these drugs were initiated. ${ }^{123}$ Nevertheless, owing to possible maternal diabetogenic effects and hepatic toxicity, the use of PIs in pregnancy should be monitored carefully, especially in the later stages. ${ }^{5,124}$

There are two characteristics of PIs that are particularly relevant to their efficacy and tolerability in pregnancy. First, large patient variability in plasma concentrations is a common feature of PIs and second, considerable data indicate that there is a significant association between PI concentration and the virologic response and/or toxicity. Thus, the physiologic changes that occur in pregnancy may lower PI plasma levels below the therapeutic minimum. ${ }^{125,126}$ In one clinical study of lopinavir (LPV), ${ }^{127}$ exposure in pregnant women resulted in LPV concentrations of about half that measured in nonpregnant adults receiving standard dosing. Further, only $18 \%$ of the women studied during the third trimester of pregnancy had LPV area under the curve (AUC) above the 10th percentile for nonpregnant adults and none exceeded the 50th percentile. ${ }^{126}$ All but one of the women were fully suppressed at delivery, however, suggesting that the plasma levels of LPV may be superior to anticipated efficacy. ${ }^{127}$ Since approximately $99 \%$ of LPV is bound to serum proteins, ${ }^{128}$ pregnancy-related decreases in this fraction could yield better viral suppression than would be anticipated from total plasma measurements.

Similar results for plasma pharmacokinetics have been reported for NFV. ${ }^{129}$ For example, during the third trimester of pregnancy, the mean difference in plasma levels, AUC, and trough concentration in NFV-treated participants was significantly $(P<0.01)$ lower in pregnant compared with nonpregnant women. ${ }^{129}$ In contrast, pharmacokinetic studies of SQV in HIV-infected pregnant women reported SQV exposures in excess of the AUC, and AUC did not change significantly during gestation, labor, and delivery. ${ }^{130}$ Similar findings were reported from a recent study using the new Invirase $^{\circledR}$ formulation of SQV (Roche Pharmaceuticals, Nutley, NJ). ${ }^{131}$ Together these findings suggest that SQV is a strong PI candidate when considering treatment options for pregnant HIV-1-infected patients.

Finally, there have been several case reports, all involving pregnant HIV patients showing multi-drug resistance, of the incorporation of other protease inhibitors in ARV regimens to prevent MTCT. Three of these involved ritonavirboosted darunavir; ${ }^{132-134}$ the other included ritonavir-boosted tipranavir. ${ }^{135}$ All births were by cesarean delivery; in none of the cases was there transmission of HIV to the newborn.
Because of their potency and limited transplacental passage protease inhibitors are ideal to be used as strategies for the prevention of MTCT. Providers need to be aware of the different pharmacokinetic issues with the diverse drugs and should choose those with proven efficacy and adequate maternal drug levels.

\section{Fusion/entry inhibitors}

The US Food and Drug Administration has designed a drug toxicity classification system. ${ }^{136}$ This system classifies drugs from $\mathrm{A}$ to $\mathrm{D}$ based on the potential risks to a fetus during pregnancy. Both enfuvirtide (ENF) and MVC are in category B (ie, drugs that, in animal reproduction studies, fail to demonstrate a risk to the fetus; however, well-controlled studies of pregnant woman have not been conducted). ${ }^{5}$ What is the likelihood that these drugs will cross the placenta? The molecular weight of ENF is $4492 \mathrm{Da}$ and therefore is too large a molecule to diffuse across the placenta. Still, MVC, with a molecular weight of $514 \mathrm{Da}$, is likely to exhibit limited transplacental diffusion. Since MVC is a substrate for the efflux transporter P-gp, this limited diffusion should be reduced further to the extent that placental transfer would be minimal. ${ }^{52}$ The chemokine coreceptor 5 inhibitor still under development, vicriviroc, has a molecular weight of $557 \mathrm{Da}$, similar to that of MVC but it has been reported in at least in vitro studies not to be a substrate for P-gp. Thus, vicriviroc should exhibit limited transplacental diffusion. ${ }^{137-139}$

\section{Integrase inhibitors}

Raltegravir (RAL) is the first integrase inhibitor to receive FDA approval. Raltegravir limits the preparatory step that inserts the viral DNA into the exposed regions of the DNA of the host cell. With a molecular weight of 483 Da (Table 1), RAL is likely to partially pass through the placenta, assuming a low affinity for the P-gp transporter. ${ }^{51}$ In preliminary animal studies, the drug was found to readily cross the placenta in rats and to a limited extent in rabbits, ${ }^{5}$ and it is classified as FDA pregnancy category $\mathrm{C}$ (ie, drugs for which safety in human pregnancy has not been determined; animal studies are either positive for fetal risk or have not been conducted). Similarly, the integrase inhibitor elvitegravir, currently under development, has a molecular weight of $448 \mathrm{Da}$ and like RAL should partially pass through the placental, assuming a low affinity for the P-gp transporter. ${ }^{140,141}$

\section{Nonpharmacologic strategies}

A major nonpharmacologic strategy to reduce the MTCT of HIV is elective cesarean delivery before the onset of 
labor. ${ }^{142,143}$ The effectiveness of elective cesarean delivery probably resides in decreasing the exposure of the fetal circulation to maternal circulation that normally occurs during labor by disruption of the placental barrier. It also avoids direct neonate contact with potentially infected maternal secretions during passage through the birth canal. This is true even if the patient was or was not receiving AZT therapy. ${ }^{142-145}$

Whether scheduled cesarean delivery offers any benefit to women with low or undetectable viral loads is not clear. For women with HIV RNA $<1000$ copies $/ \mathrm{mL}$, the data are insufficient to determine if MTCT rates would be further reduced by elective cesarean delivery. One retrospective chart review study of 2539 women receiving HAART found a MTCT rate of $1.3 \%$. Women with HIV RNA levels of $<1000$ copies $/ \mathrm{mL}$ were reported to have MTCT rates of $0.8 \%$ with scheduled cesarean delivery and $0.5 \%$ with all other delivery modes. ${ }^{146} \mathrm{In}$ another report from the European Collaborative Study of 4525 women receiving HAART, ${ }^{147}$ the overall MTCT rate was $2.9 \%$. In this study of a subset of 560 women with undetectable HIV RNA levels, scheduled cesarean delivery was associated with a significant reduction in MTCT in univariate analyses $(P=0.0004) .{ }^{147}$ However, after adjustment for ARV therapy (none versus any), the effect was no longer significant $(P=0.36)$. Very similar results, suggesting the possibility of vaginal delivery in cases of adequate viral suppression, were reported in the study of the French Perinatal Cohort, where elected cesarean section was associated with a lower MCTC risk in the overall population but not among women delivering with viral loads less than 400 copies $/ \mathrm{mL}$. Among the 2856 women with viral loads $<400$ copies $/ \mathrm{mL}$, the MTCT rate was $0.6 \%$, and among the 1338 mothers with viral loads $<50$ copies $/ \mathrm{mL}$, the rate was only $0.4 \% .{ }^{148}$ It should be noted, moreover, that cesarean deliveries carry an additional risk of postpartum morbidity. In a retrospective study of $401 \mathrm{HIV-infected}$ women, the incidence of serious postpartum complications was $12 \%$ after emergency cesarean deliveries, $6.4 \%$ after elective cesarean deliveries, and $4 \%$ after vaginal deliveries. ${ }^{149}$ A cohort study of 299 vaginal deliveries, 260 elective cesarean deliveries and 139 cesareans with ruptured membranes in Latin America and the Caribbean showed low morbidity associated to elective cesareans with an unadjusted OR of 1.16 (95\% CI: 0.5, 2.7). Morbidity was higher (odds ratio (OR), 2.96; 95\% CI: 1.3, 6.7) for those with ruptured membranes or procedures after labor. ${ }^{150}$ Taken together, the data from these various reports are not sufficient to confirm or to rule out a benefit from scheduled cesarean delivery among women with HIV RNA $<1000$ copies/mL who are receiving HAART. ${ }^{147}$

The American College of Obstetricians and Gynecologists (ACOG) Committee on Obstetric Practice and the Perinatal HIV Guidelines Working Group have issued guidelines for the best route of delivery for pregnant women with HIV infection. ${ }^{151}$ For women with HIV RNA levels $>1000$ copies $/ \mathrm{mL}$ and who are receiving ARVs, both panels recommend consideration of scheduled cesarean delivery for women near to the time of delivery. ${ }^{151}$ For women with HIV RNA levels $<1000$ copies/mL, the decisions on the mode of delivery should be individualized. GermanAustrian recommendations for HIV therapy in pregnancy closely reflect those of the ACOG and the Perinatal HIV Guidelines Working Group. ${ }^{152}$ There may be other maternal reasons for the choice of an elective cesarean delivery. The ACOG recommends that patient's autonomy regarding their decision regarding route of delivery must be respected, and ultimately the decision must be individualized according to circumstances. ${ }^{151}$

If the decision is made to perform a scheduled cesarean delivery to prevent MTCT, ACOG recommends that it be done at 38 weeks' gestation as determined by the best clinical and sonographic estimates and to avoid amniocentesis. ${ }^{151}$ Unfortunately, in many resource-constrained settings, elective cesarean delivery is seldom feasible. ${ }^{153}$ Therefore, in these settings, the efforts to prevent HIV infection in infants are limited to reducing MTCT around the time of labor and delivery, which generally accounts for one-third to two-thirds of overall transmission (depending on whether the mother then breastfeeds). ${ }^{1}$

The other nonpharmacologic method that can reduce the MTCT of HIV is avoidance of breastfeeding. Breast milk, which can carry HIV, can increase the likelihood of MTCT ${ }^{25}$ The highest concentration of HIV per $\mathrm{mL}$ of breast milk is found in colostrum, or early milk. ${ }^{154}$ It is not clear to what extent breastfeeding influences the efficacy of ARV therapy since only a few trials in breastfeeding populations (all conducted in Africa) report HIV transmission rates beyond 4 to 8 weeks and the results differ by study. ${ }^{9,155-159}$ In the HIVNET 012 trial, ${ }^{157}$ the initial reduction in perinatal transmission was maintained at 18 months in a breastfeeding population, a finding supported by those in the DITRAME (Diminution de la Transmission Mere-Enfant) trial. ${ }^{156-160}$ In contrast, the PETRA (Perinatal Transmission) study ${ }^{159}$ examined the efficacy of short-course treatment regimens with AZT and 3TC in a predominantly breastfeeding population and reported that early reductions in HIV infection 
rates and HIV infection or mortality at 4 to 8 weeks declined and became statistically nonsignificant by 18 months. A prospective study following 236 infants from birth until 24 months of age born to HIV-positive mothers in Harare, Zimbabwe, ${ }^{161}$ reported that breastfed infants had the greatest cumulative relative risk of MTCT of HIV-1, followed by mixed-fed infants, with the highest incidences occurring within the first 3 months. The guidelines established by the Perinatal HIV Guidelines Working Group and the WHO do not recommend breastfeeding for HIV-infected women where safe, affordable, and feasible alternatives are available and culturally acceptable. , $^{5,162}$

Where avoidance of breastfeeding is not feasible, however, multiple studies have evaluated the role of ARV prophylaxis in preventing HIV transmission. In the MASHI Study, breastfeeding with a concurrent six months of AZT infant prophylaxis was not as effective as formula feeding with a concurrent one month of AZT infant prophylaxis in preventing HIV transmission to the infants at seven months ( $9.0 \%$ vs 5.6\%, respectively); however the formula-feeding regimen had a higher cumulative mortality rate than the breastfeeding regimen ( $9.3 \%$ vs. $4.9 \%)$, resulting in comparable HIV-free survival rates at 18 months. ${ }^{163}$ In the Mitra Study, in which breastfed infants received daily 3 TC for up to six months, the cumulative infection rate, $3.8 \%$ at six weeks, increased only to $4.9 \%$ at six months. ${ }^{164}$ Other studies have examined the efficacy of giving HAART to mothers during breastfeeding. In the single-arm Kisumu Breastfeeding Study in which maternal HAART was continued until weaning at six months and infants received a single dose of NVP at birth, the infant HIV infection rate at 12 months was 5.9\%. ${ }^{165}$ In the Drug Resource Enhancement against AIDS and Malnutrition (DREAM) program, MTCT rates at six months were $0.8 \%$ among breastfed infants of women receiving HAART and $1.8 \%$ among formula-fed infants $(P=0.38) .{ }^{166}$ The AMATA Study compared formula feeding to breastfeeding in women who all received NNRTI-based triple therapy; $1.4 \%$ of children were already infected at birth there but there were no additional children infected through breastfeeding. ${ }^{167}$ While further work is required, to better define these MTCT rates, these data support the continued administration of HAART to women in contexts where suspension of breastfeeding is impractical.

\section{Mother and child perinatal/ postnatal HIV care: the future}

As women comprise a growing proportion of the HIV-infected population, it is important to consider gender-specific, perinatal, and postnatal issues when assessing treatment options. Different ARV pharmacokinetic profiles in women (relative to men) and in pregnant versus nonpregnant women merit more research to define therapeutic ranges in drug metabolism before and during pregnancy. The maternal and fetal efficacy and toxicity of ARVs remain important concerns for women of childbearing potential and warrant future studies to ensure the safety and long-term well-being of both mother and fetus.

\section{Acknowledgments}

Editorial assistance was provided by Diann Glickman, PharmD of Zola Associates and supported by Roche. Dr Zorrilla and Dr Tamayo-Agrait have no disclosures related to this manuscript. Dr Zorrilla is supported by:1U01 AI69415-01 [NIAID, NIH] University of Puerto Rico Clinical Trials Unit (UPR-CTU); 5U54RR019507-05 [NCRR, NIH] Puerto Rico Comprehensive Center (for the study of) HIV Disparities (PR-CCHD) and. and [NIMH, NIH] 1 R25 MH 083617-01. Dr Tamayo-Agrait is supported by: 1U01 AI69415-01 University of Puerto Rico Clinical Trials Unit (UPR-CTU); 5U54RR019507-05 Puerto Rico Comprehensive Center (for the study of) HIV Disparities (PR-CCHD).

\section{References}

1. UNAIDS/WHO. Global summary of the AIDS epidemic, December 2008. [cited 2009 November]. Available from: http://data.unaids. org/pub/Report/2009/2009_epidemic_update_en.pdf

2. The Working Group on Mother-To-Child Transmission of HIV. Rates of mother-to-child transmission of HIV-1 in Africa, America, and Europe: results from 13 perinatal studies. J Acquir Immune Defic Syndr Hum Retrovirol. 1995;8(5):506-510.

3. United Nations International Children's Emergency Fund. Progress for children. A child survival report card. 2004; volume 1:1-22. [cited 2009 June 23]. Available from: http://www.unicef.org/publications/ index_23557.html.

4. Walker N, Schwartlander B, Bryce J. Meeting international goals in child survival and HIV/AIDS. Lancet. 2002;360(9329):284-289.

5. Public Health Service Task Force. Recommendations for use of antiretroviral drugs in pregnant HIV infected women for maternal health and interventions to reduce perinatal HIV transmission in the United States April 29, 2009. [cited 2009 June]. Available from: http://aidsinfo.nih. gov/contentfiles/PerinatalGL.pdf.

6. Coll O, Fiore S, Floridia M, et al. Pregnancy and HIV infection: a European consensus on management. AIDS. 2002;16(Suppl 2):S1-S18.

7. Burdge DR, Money DM, Forbes JC, et al. Canadian consensus guidelines for the management of pregnancy, labour and delivery and for postpartum care in HIV-positive pregnant women and their offspring (summary of 2002 guidelines). CMAJ. 2003;168(13):1671-1674.

8. Mofenson LM. Advances in the prevention of vertical transmission of human immunodeficiency virus. Semin Pediatr Infect Dis. 2003;14(4):295-308.

9. Guay LA, Musoke P, Fleming T, et al. Intrapartum and neonatal single-dose nevirapine compared with zidovudine for prevention of mother-to-child transmission of HIV-1 in Kampala, Uganda: HIVNET 012 randomised trial. Lancet. 1999;354(9181):795-802. 
10. Christie CD, Steel-Duncan J, Palmer P, et al. Paediatric and perinatal HIV/AIDS in Jamaica: an international leadership initiative, 2002-2007 West Indian Med J. 2008;57(3):204-215.

11. Zorrilla CD, Tamayo Agrait V, Febo I, et al. Reduction in the perinatal HIV transmission: the experience at the Maternal Infant Studies Center and Gamma Project at the University of Puerto Rico School of Medicine. P R Health Sci J. 2007;26(4):329-335.

12. Connor EM, Sperling RS, Gelber R, et al. Reduction of maternal-infant transmission of human immunodeficiency virus type 1 with zidovudine treatment. Pediatric AIDS Clinical Trials Group Protocol 076 Study Group. N Engl J Med. 1994;331(18):1173-1180.

13. Mofenson L, Taylor AW, Rogers M, et al; for Centers for Disease Control and Prevention (CDC). Achievements in public health Reduction in perinatal transmission of HIV infection - United States, 1985-2005. MMWR. 2006;55(21):592-597.

14. HIV-infected pregnant women and vertical transmission in Europe since 1986. European Collaborative Study. AIDS. 2001;15(6): 761-770.

15. Ioannidis JP, Abrams EJ, Ammann A, et al. Perinatal transmission of human immunodeficiency virus type 1 by pregnant women with RNA virus loads $<1000$ copies/ml. J Infect Dis. 2001;183(4): 539-545.

16. Garcia PM, Kalish LA, Pitt J, et al. Maternal levels of plasma human immunodeficiency virus type 1 RNA and the risk of perinatal transmission. Women and Infants Transmission Study Group. N Engl J Med. 1999;341(6):394-402.

17. Cooper ER, Charurat M, Mofenson L, et al. Combination antiretroviral strategies for the treatment of pregnant HIV-1-infected women and prevention of perinatal HIV-1 transmission. J Acquir Immune Defic Syndr. 2002;29(5):484-494.

18. Mandelbrot L, Landreau-Mascaro A, Rekacewicz C, et al. Lamivudinezidovudine combination for prevention of maternal-infant transmission of HIV-1. JAMA. 2001;285(16):2083-2093.

19. Dorenbaum A, Cunningham CK, Gelber RD, et al. Two-dose intrapartum/newborn nevirapine and standard antiretroviral therapy to reduce perinatal HIV transmission: a randomized trial. JAMA. 2002;288(2):189-198.

20. Lallemant M, Jourdain G, Le CS, et al. A trial of shortened zidovudine regimens to prevent mother-to-child transmission of human immunodeficiency virus type 1. Perinatal HIV Prevention Trial (Thailand) Investigators. $N$ Engl J Med. 2000;343(14): 982-991.

21. Halpern SD. Shortened zidovudine regimens to prevent mother-to-child transmission of HIV-1. N Engl J Med. 2001;344(4):307.

22. Eyakuze C, Jones DA, Starrs AM, Sorkin N. From PMTCT to a more comprehensive AIDS response for women: a much-needed shift. Dev World Bioeth. 2008;8(1):33-42

23. World Health Organization Department of HIV/AIDS: Prevention of Mother-To-Child Transmission (PMTCT) Briefing Note. October 1, 2007, Accessed August 22, 2009; http://www.who.int/hiv/pub/toolkits/PMTCT\%20HIV\%20Dept\%20brief\%20Oct\%2007.pdf

24. Kovacs A, Chan LS, Chen ZC, et al. HIV-1 RNA in plasma and genital tract secretions in women infected with HIV-1. J Acquir Immune Defic Syndr. 1999;22(2):124-131.

25. Dunn DT, Newell ML, Ades AE, Peckham CS. Risk of human immunodeficiency virus type 1 transmission through breastfeeding. Lancet. 1992;340(8819):585-588.

26. Perinatal HIV Guidelines Working Group. Public Health Service Task Force Recommendations for Use of Antiretroviral Drugs in Pregnant HIV-Infected Women for Maternal Health and Interventions to Reduce Perinatal HIV Transmission in the United States. April 29, 2009; pp 1-90. Accessed August 22, 2009; http://aidsinfo.nih.gov/ContentFiles/PerinatalGL.pdf

27. Faupel-Badger JM, Hsieh CC, Troisi R, Lagiou P, Potischman N. Plasma volume expansion in pregnancy: implications for biomarkers in population studies. Cancer Epidemiol Biomarkers Prev. 2007; 16(9):1720-1723.
28. Smith MC, Moran P, Ward MK, Davison JM. Assessment of glomerular filtration rate during pregnancy using the MDRD formula. BJOG. 2008;115(1):109-112.

29. Wadelius M, Darj E, Frenne G, Rane A. Induction of CYP2D6 in pregnancy. Clin Pharmacol Ther. 1997;62(4):400-407.

30. Tracy TS, Venkataramanan R, Glover DD, Caritis SN. Temporal changes in drug metabolism (CYP1A2, CYP2D6 and CYP3A activity) during pregnancy. Am J Obstet Gynecol. 2005;192(2):633-639.

31. Pacifici GM, Nottoli R. Placental transfer of drugs administered to the mother. Clin Pharmacokinet. 1995;28(3):235-269.

32. Tuntland T, Nosbisch C, Baughman WL, Massarella J, Unadkat JD. Mechanism and rate of placental transfer of zalcitabine (2', 3'-dideoxycytidine) in Macaca nemestrina. Am J Obstet Gynecol. 1996;174(3):856-863.

33. Tuntland T, Nosbisch C, Unadkat JD. Effect of pregnancy, mode of administration and neonatal age on the pharmacokinetics of zalcitabine (2', 3'-dideoxycytidine) in the pigtailed macaque (Macaca nemestrina). J Antimicrob Chemother. 1997;40(5):687-693.

34. Chappuy H, Treluyer JM, Jullien V, et al. Maternal-fetal transfer and amniotic fluid accumulation of nucleoside analogue reverse transcriptase inhibitors in human immunodeficiency virus-infected pregnant women. Antimicrob Agents Chemother. 2004;48(11): $4332-4336$.

35. Bawdon RE. The ex vivo human placental transfer of the anti-HIV nucleoside inhibitor abacavir and the protease inhibitor amprenavir. Infect Dis Obstet Gynecol. 1998;6(6):244-246.

36. Clark TN, White CA, Bartlett MG. Determination of abacavir in maternal plasma, amniotic fluid, fetal and placental tissues by a polarity switching liquid chromatography/tandem mass spectrometry method. Rapid Commun Mass Spectrom. 2004;18(4):405-411.

37. Lewis SR, White CA, Bartlett MG. Simultaneous determination of abacavir and zidovudine from rat tissues using HPLC with ultraviolet detection. J Chromatogr B Analyt Technol Biomed Life Sci. 2007;850(1-2):45-52.

38. Chi BH, Sinkala M, Mbewe F, et al. Single-dose tenofovir and emtricitabine for reduction of viral resistance to non-nucleoside reverse transcriptase inhibitor drugs in women given intrapartum nevirapine for perinatal HIV prevention: an open-label randomised trial. Lancet. 2007;370(9600):1698-1705.

39. Szczech GM, Wang LH, Walsh JP, Rousseau FS. Reproductive toxicology profile of emtricitabine in mice and rabbits. Reprod Toxicol. 2003;17(1):95-108.

40. Rescriptor ${ }^{\circledR}$ [delavirdine prescribing information]. New York, NY; Pfizer Inc; 2008.

41. Sustiva ${ }^{\mathbb{R}}$ [efavirenz capsules and tablets prescribing information]. Princeton, NJ: Bristol-Myers Squibb Co; 2009.

42. Viramune ${ }^{\circledR}$ [nevirapine prescribing information]. Ingelheim, Germany; Boehringer-Ingelheim; 2008.

43. United States National Library of Medicine. ChemIDPlus Lite. Etravirine. [cited 2009 June 29]. Available from: http://chem.sis.nlm.nih. gov/chemidplus/chemidlite.jsp

44. Saitoh A, Hull AD, Franklin P, Spector SA. Myelomeningocele in an infant with intrauterine exposure to efavirenz. J Perinatol. 2005;25(8):555-556.

45. DeSantis M, Carducci B, De Santis L, Cavaliere AF, Straface G. Periconceptional exposure to efavirenz and neural tube defects. Arch Intern Med. 2002;162(3):355.

46. Jeantils V, Khuong MA, Delassus JL, et al. Efavirenz (Sustiva) in pregnancy: a study about 12 HIV patients. Gynecol Obstet Fertil. 2006;34(7-8):593-596.

47. Mirochnick M, Fenton T, Gagnier P, et al. Pharmacokinetics of nevirapine in human immunodeficiency virus type 1-infected pregnant women and their neonates. Pediatric AIDS Clinical Trials Group Protocol 250 Team. J Infect Dis. 1998;178(2):368-374

48. Marzolini C, Rudin C, Decosterd LA, et al; Swiss Mother + Child HIV Cohort Study. Transplacental passage of protease inhibitors at delivery. AIDS. 2002;12;16(6):889-893. 
49. Gingelmaier A, Kurowski M, Kästner R, et al. Placental transfer and pharmacokinetics of lopinavir and other protease inhibitors in combination with nevirapine at delivery. AIDS. 2006;(13): 1737-1743.

50. Nightingale SL. From the Food and Drug Administration. JAMA. 1998;280(17):1472.

51. Isentress ${ }^{\circledR}$ [raltegravir tablets prescribing information]. Whitehouse Station, NJ: Merck and Co; 2009.

52. Selzentry ${ }^{\circledR}$ [maraviroc tablets prescribing information]. New York, NY: Pfizer Inc; 2009.

53. Fuzeon ${ }^{\circledR}$ [enfuvirtide for injection prescribing information]. Nutley, NJ and Durham, NC: Roche and Trimeris Inc; 2008.

54. Agenerase ${ }^{\circledR}$ [amprenavir prescribing information]. Research Triangle Park, NC and Cambridge, MA: GlaxoSmithKline and Vertex Pharmaceuticals Incorporated; 2005.

55. Crixivan ${ }^{\circledR}$ [indinavir sulphate capsules prescribing information]. Whitehouse Station, NJ: Merck and Co; 2008.

56. Kaletra ${ }^{\circledR}$ [lopinavir prescribing information]. Chicago, IL: Abbott Laboratories; 2008.

57. Viracept ${ }^{\mathbb{\circledR}}$ [nelfinavir mesylate tablets and oral powder prescribing information], San Diego, CA: Agouron Pharmaceuticals; 2008.

58. Norvir ${ }^{\mathbb{B}}$ [ritonavir prescribing information]. Chicago, IL: Abbott Laboratories; 2008.

59. Invirase ${ }^{\circledR}$ [saquinavir mesylate capsules and tablets prescribing information]. Nutley, NJ: Roche Pharmaceuticals; 2007.

60. Williams GC, Sinko PJ. Oral absorption of the HIV protease inhibitors: a current update. Adv Drug Deliv Rev. 1999;39(1-3):211-238.

61. Longer M, Shetty B, Zamansky I, Tyle P. Preformulation studies of a novel HIV protease inhibitor, AG1343. J Pharm Sci. 1995;84(9):1090-1093.

62. Gimenez F, Fernandez C, Mabondzo A. Transport of HIV protease inhibitors through the blood-brain barrier and interactions with the efflux proteins, P-glycoprotein and multidrug resistance proteins. J Acquir Immune Defic Syndr. 2004;36(2):649-658.

63. Glynn SL, Yazdanian M. In vitro blood-brain barrier permeability of nevirapine compared to other HIV antiretroviral agents. J Pharm Sci. 1998;87(3):306-310.

64. Kliger Y, Gallo SA, Peisajovich SG, et al. Mode of action of an antiviral peptide from HIV-1. Inhibition at a post-lipid mixing stage. J Biol Chem. 2001;276(2):1391-1397.

65. Hansch C, Bjorkroth JP, Leo A. Hydrophobicity and central nervous system agents: on the principle of minimal hydrophobicity in drug design. J Pharm Sci. 1987;76(9):663-687.

66. Syme MR, Paxton JW, Keelan JA. Drug transfer and metabolism by the human placenta. Clin Pharmacokinet. 2004;43(8):487-514.

67. Myllynen P, Pasanen M, Vahakangas K. The fate and effects of xenobiotics in human placenta. Expert Opin Drug MetabToxicol. 2007;3(3):331-346.

68. Young AM, Allen CE, Audus KL. Efflux transporters of the human placenta. Adv Drug Deliv Rev. 2003;55(1):125-132.

69. Ritter CA, Jedlitschky G, Meyer Zu, et al. Cellular export of drugs and signaling molecules by the ATP-binding cassette transporters MRP4 (ABCC4) and MRP5 (ABCC5). Drug Metab Rev. 2005;3(1): 253-278.

70. St-Pierre MV, Serrano MA, Macias RI, et al. Expression of members of the multidrug resistance protein family in human term placenta. Am J Physiol Regul Integr Comp Physiol. 2000;279(4): R1495-R1503.

71. St-Pierre MV, Ugele B, Gambling L, Shiverick KT. Mechanisms of drug transfer across the human placenta - A workshop report. Placenta. 2002;23(Suppl A):S159-164.

72. Lee JS, Paull K, Alvarez M, et al. Rhodamine efflux patterns predict P-glycoprotein substrates in the National Cancer Institute drug screen. Mol Pharmacol. 1994;46(4):627-638.

73. Scala S, Akhmed N, Rao US, et al. P-glycoprotein substrates and antagonists cluster into two distinct groups. Mol Pharmacol. 1997;51(6):1024-1033.
74. Evseenko D, Paxton JW, Keelan JA. Active transport across the human placenta: impact on drug efficacy and toxicity. Expert Opin Drug Metab Toxicol. 2006;2(1):51-69.

75. MacFarland A, Abramovich DR, Ewen SW, Pearson CK. Stage-specific distribution of P-glycoprotein in first-trimester and full-term human placenta. Histochem J. 1994;26(5):417-423.

76. Nagashige M, Ushigome F, Koyabu N, et al. Basal membrane localization of MRP1 in human placental trophoblast. Placenta. 2003;24(10):951-958.

77. Williams GC, Liu A, Knipp G, Sinko PJ. Direct evidence that saquinavir is transported by multidrug resistance-associated protein (MRP1) and canalicular multispecific organic anion transporter (MRP2). Antimicrob Agents Chemother. 2002;46(11):3456-3462.

78. Ambudkar SV, Dey S, Hrycyna CA, Ramachandra M, Pastan I, Gottesman MM. Biochemical, cellular, and pharmacological aspects of the multidrug transporter. Annu Rev Pharmacol Toxicol. 1999;39:361-398.

79. Chappuy H, Treluyer JM, Rey E, et al. Maternal-fetal transfer and amniotic fluid accumulation of protease inhibitors in pregnant women who are infected with human immunodeficiency virus. Am J Obstet Gynecol. 2004;191(2):558-562.

80. Newell ML. Mechanisms and timing of mother-to-child transmission of HIV-1. AIDS. 1998;12(8):831-837.

81. Liebes L, Mendoza S, Wilson D, Dancis J. Transfer of zidovudine (AZT) by human placenta. J Infect Dis. 1990;161(2):203-207.

82. Boal JH, Plessinger MA, van den Reydt C, Miller RK. Pharmacokinetic and toxicity studies of AZT (zidovudine) following perfusion of human term placenta for 14 hours. Toxicol Appl Pharmacol. 1997;143(1):13-21.

83. Huisman MT, Smit JW, Schinkel AH. Significance of P-glycoprotein for the pharmacology and clinical use of HIV protease inhibitors. AIDS. 2000;14(3):237-242.

84. Averitt D. HIV and pregnancy: tough choices . . . and the right to choose. J Assoc Nurses AIDS Care. 2002;13(3):11-12.

85. Chappuy H, Treluyer JM, Jullien V, et al. Maternal-fetal transfer and amniotic fluid accumulation of nucleoside analogue reverse transcriptase inhibitors in human immunodeficiency virus-infected pregnant women. Antimicrob Agents Chemother. 2004;48(11):4332-4336.

86. Antiretroviral Pregnancy Registry. [cited 2009 June]. Available from: http://www.apregistry.com/forms/interim_report.pdf.

87. Perinatal Safety Review Working Group. Nucleoside exposure in the children of HIV-infected women receiving antiviral drugs: absence of clear evidence for mitochondrial disease in children who died before 5 years of age in five United States cohorts. J Acquir Immune Defic Syndr Hum Retrovirol. 2000;15(3):261-268.

88. Barret B, Tardieu M, Rustin P, et al. Persistent mitochondrial dysfunction in HIV-1-exposed but uninfected infants: clinical screening in a large prospective cohort. AIDS. 2003;17(12):1769-1785.

89. Tardieu M, Brunelle F, Raybaud C, et al. Cerebral MR imaging in uninfected children born to HIV-seropositive mothers and perinatally exposed to zidovudine. Am J Neuroradiol. 2005;26(4): 695-701.

90. Alimenti A, Burdge DR, Ogilvie GS, Money DM, Forbes JC. Lactic acidemia in human immunodeficiency virus-uninfected infants exposed to perinatal antiretroviral therapy. Pediatr Infect Dis J. 2003;22(9):782-789.

91. Sarner L, Fakoya A. Acute onset lactic acidosis and pancreatitis in the third trimester of pregnancy in HIV-1 positive women taking antiretroviral medication. Sex Transm Infect. 2002;78(1): 58-59.

92. Hill JB, Sheffield JS, Zeeman GG, Wendel GD. Hepatotoxicity with antiretroviral treatment of pregnant women. Obstet Gynecol. 2001;98(5 part 2):909-911.

93. Shiramizu B, Shikuma KM, Kamemoto L, et al. Placenta and cord blood mitochondrial DNA toxicity in HIV-infected women receiving nucleoside reverse transcriptase inhibitors during pregnancy. J Acquir Immune Defic Syndr. 2003;32(4):370-374. 
94. Poirier MC, Divi RL, Al-Harthi L, et al. Long-term mitochondrial toxicity in HIV-uninfected infants born to HIV-infected mothers. J Acquir Immune Defic Syndr 2003;33(2):175-183.

95. Divi RL, Leonard SL, Walker BL, et al. Erythocebus patas monkey offspring exposed perinatally to NRTIs sustain skeletal muscle mitochondrial compromise at birth at 1 year of age. Toxicol Sci. 2007;99(1):203-213.

96. Tarantal AF, Castillo A, Ekert JE, Bischofberger N, Martin RB. Fetal and maternal outcome after administration of tenofovir to gravid rhesus monkeys (Macaca mulatta). J Acquir Immune Defic Syndr. 2002;29(3):207-220.

97. Woodward CL, Hall AM, Williams IG, et al. Tenofovir-associated renal and bone toxicity. HIV Med. 2009;10(8):482-487.

98. Gafni RI, Hazra R, Reynolds JC, et al. Tenofovir disoproxil fumarate and an optimized background regimen of antiretroviral agents as salvage therapy: impact on bone mineral density in HIV-infected children. Pediatrics. 2006 Sep; 118(3):e711-718.

99. Viganò A, Zuccotti GV, Martelli L, et al. Renal safety of tenofovir in HIV-infected children: a prospective, 96-week longitudinal study. Clin Drug Investig. 2007;27(8):573-581.

100. Riordan A, Judd A, Boyd K, et al; Collaborative HIV Paediatric Study. Tenofovir use in human immunodeficiency virus-1-infected children in the United Kingdom and Ireland. Pediatr Infect Dis J. 2009;28(3):204-209.

101. Chi BH, Chintu N, Cantrell RA, et al. Addition of single-dose tenofovir and emtricitabine to intrapartum nevirapine to reduce perinatal HIV transmission. J Acquir Immune Defic Syndr. 2008;48(2):220-223.

102. Arrivé E, Chaix ML, Nerrienet E, et al. TEmAA ANRS 12109 Study group. Tolerance and viral resistance after single-dose nevirapine with tenofovir and emtricitabine to prevent vertical transmission of HIV-1. AIDS. 2009;23(7):825-833.

103. Foster C, Lyall H, Olmscheid B, Pearce G, Zhang S, Gibb DM. Tenofovir disoproxil fumarate in pregnancy and prevention of motherto-child transmission of HIV-1: is it time to move on from zidovudine? HIV Med. 2009;10(7):397-406.

104. Esnouf R, Ren J, Ross C, Jones Y, Stammers D, Stuart D. Mechanism of inhibition of HIV-1 reverse transcriptase by non-nucleoside inhibitors. Nat Struct Biol. 1995;2(4):303-308.

105. Taha TE, Kumwenda NI, Hoover DR, et al. Nevirapine and zidovudine at birth to reduce perinatal transmission of HIV in an African setting: a randomized controlled trial. JAMA. 2004;292(2):202-209.

106. Moodley D, Moodley J, Coovadia H, et al. A multicenter randomized controlled trial of nevirapine versus a combination of zidovudine and lamivudine to reduce intrapartum and early postpartum mother-to-child transmission of human immunodeficiency virus type 1. J Infect Dis. 2003;187(5):725-735.

107. Jackson JB, Becker-Pergola G, Guay LA, et al. Identification of the $\mathrm{K} 103 \mathrm{~N}$ resistance mutation in Ugandan women receiving nevirapine to prevent HIV-1 vertical transmission. AIDS. 2000;14(11):111-115.

108. Flys T, Nissley DV, Claasen CW, et al. Sensitive drug-resistance assays reveal long-term persistence of HIV-1 variants with the K103N nevirapine (NVP) resistance mutation in some women and infants after the administration of single-dose NVP: HIVNET 012. J Infect Dis. 2005;192(1):24-29.

109. Stringer JS, Sinkala M, Chapman V, et al. Timing of the maternal drug dose and risk of perinatal HIV transmission in the setting of intrapartum and neonatal single-dose nevirapine. AIDS. 2003;17(11):1659-1665.

110. Flys TS, Chen S, Jones DC, et al. Quantitative analysis of HIV-1 variants with the $\mathrm{K} 103 \mathrm{~N}$ resistance mutation after single-dose nevirapine in women with HIV-1 subtypes A, C, and D. J Acquir Immune Defic Syndr. 2006;42(5):610-613.

111. Muro E, Droste JA, Hofstede HT, Bosch M, Dolmans W, Burger DM. Nevirapine plasma concentrations are still detectable after more than 2 weeks in the majority of women receiving single-dose nevirapine: implications for intervention studies. J Acquir Immune Defic Syndr. 2005;39(4):419-421.
112. Eshleman SH, Mracna M, Guay LA, et al. Selection and fading of resistance mutations in women and infants receiving nevirapine to prevent HIV-1 vertical transmission (HIVNET 012). AIDS. 2001;15(15):1951-1957.

113. Lyons FE, Coughlan S, Byrne CM, Hopkins SM, Hall WW, Mulcahy FM. Emergence of antiretroviral resistance in HIV-positive women receiving combination antiretroviral therapy in pregnancy. AIDS. 2005;19(1):63-67.

114. Jourdain G, Ngo-Giang-Huong N, Le Coeur S, et al; Perinatal HIV Prevention Trial Group. Intrapartum exposure to nevirapine and subsequent maternal responses to nevirapine-based antiretroviral therapy. N Engl J Med. 2004;351(3):229-240.

115. McIntyre J. Addition of short course combivir (CBV) to single dose viramune [sdNVP) for prevention of mother to child transmission (MTCT) of HIV-1 can significantly decrease the subsequent development of maternal NNRTI-resistant virus. Proceedings of the 15th International AIDS Conference; 2004 Jul 11-16, Bangkok, Thailand.

116. Fundaro C, Genovese O, Rendeli C, Tamburrini E, Salvaggio E. Myelomeningocele in a child with intrauterine exposure to efavirenz. AIDS. 2002;16(2):299-300.

117. Furfine ES, D’Souza E, Ingold KJ, Leban JJ, Spector T, Porter DJ. Two-step binding mechanism for HIV protease inhibitors. Biochemistry. (Moscow) 1992;31(34):7886-7891.

118. Lorenzi P, Spicher VM, Laubereau B, et al. Antiretroviral therapies in pregnancy: maternal, fetal and neonatal effects. Swiss HIV Cohort Study, the Swiss Collaborative HIV and Pregnancy Study, and the Swiss Neonatal HIV Study. AIDS. 1998;12(18): 241-247.

119. Marzolini C, Rudin C, Decosterd LA, et al. Transplacental passage of protease inhibitors at delivery. AIDS. 2002;16(6): 889-893.

120. Tuomala RE, Shapiro DE, Mofenson LM, et al. Antiretroviral therapy during pregnancy and the risk of an adverse outcome. N Engl J Med. 2002;346(24):1863-1870.

121. Tuomala RE, Watts DH, Li D, et al. Improved obstetric outcomes and few maternal toxicities are associated with antiretroviral therapy, including highly active antiretroviral therapy during pregnancy. J Acquir Immune Defic Syndr. 2005;38(4):449-473.

122. Thorne C, Patel D, Newell ML. Increased risk of adverse pregnancy outcomes in HIV-infected women treated with highly active antiretroviral therapy in Europe. AIDS. 2004;18(17): 2337-2379.

123. Morris AB, Dobles AR, Cu-Uvin S, et al. Protease inhibitor use in 233 pregnancies. J Acquir Immune Defic Syndr. 2005;40(1): 30-33.

124. El Beitune P, Duarte G, Foss MC, et al. Effect of antiretroviral agents on carbohydrate metabolism in HIV-1 infected pregnant women. Diabetes Metab Res Rev. 2006;22(1):59-63.

125. Acosta EP, Kakuda TN, Brundage RC, Anderson PL, Fletcher CV. Pharmacodynamics of human immunodeficiency virus type 1 protease inhibitors. Clin Infect Dis. 2000;30(Suppl 2):S151-S159.

126. Mirochnick M, Capparelli E. Pharmacokinetics of antiretrovirals in pregnant women. Clin Pharmacokinet. 2004;43(15): 1071-1087.

127. Stek AM, Mirochnick M, Capparelli E, et al. Reduced lopinavir exposure during pregnancy. AIDS. 2006;20(15):1931-1939.

128. Boffito M, Hoggard PG, Lindup WE, et al. Lopinavir protein binding in vivo through the 12-hour dosing interval. Ther Drug Monit. 2004;26(1):35-39.

129. Villani P, Floridia M, Pirillo MF, et al. Pharmacokinetics of nelfinavir in HIV-1-infected pregnant and nonpregnant women. $\mathrm{Br} \mathrm{J} C \mathrm{Cin}$ Pharmacol. 2006;62(3):309-315.

130. Acosta EP, Bardeguez A, Zorrilla CD, et al. Pharmacokinetics of saquinavir plus low-dose ritonavir in human immunodeficiency virus-infected pregnant women. Antimicrob Agents Chemother. 2004;48(2):430-436. 
131. van der Lugt J, on Behalf of the SARA Study Team. The influence of pregnancy on the pharmacokinetics of saquinavir boosted by low-dose ritonavir (1000/100 mg BID) in HIV-infected pregnant women. Proceedings of the 9th International Workshop on Clinical Pharmacology of HIV Therapy; 2008 Apr 7-9, New Orleans, LA, USA.

132. Sued O, Lattner J, Gun A, et al. Use of darunavir and enfuvirtide in a pregnant woman. Int J STD AIDS. 2008;19(12):866-867.

133. Furco A, Gosrani B, Nicholas S, et al. Successful use of darunavir, etravirine, enfuvirtide and tenofovir/emtricitabine in pregnant woman with multiclass HIV resistance. AIDS. 2009 Jan 28;23(3): 434-435.

134. Ripamonti D, Cattaneo D, Cortinovis M, Maggiolo F, Suter F. Transplacental passage of ritonavir-boosted darunavir in two pregnant women. Int J STD AIDS.2009;20(3):215-216.

135. Wensing AM, Boucher CA, van Kasteren M, van Dijken PJ, Geelen SP, Juttmann JR. Prevention of mother-to-child transmission of multi-drug resistant HIV-1 using maternal therapy with both enfuvirtide and tipranavir. AIDS. 2006;20(10):1465-1467.

136. Perinatology.com. U.S. FDA Use-in pregnancy ratings. [cited 2009 June] Accessed November 2009. Available from: http://www. perinatology.com/exposures/Drugs/FDACategories.htm.

137. Strizki JM, Tremblay C, Xu S, et al. Discovery and characterization of vicriviroc ( $\mathrm{SCH} 417690$ ), a CCR5 antagonist with potent activity against human immunodeficiency virus type 1. Antimicrob Agents Chemother. 2005;49(12): 4911-4919.

138. Wilkin TJ, Su Z, Kuritzkes DR, et al. HIV type 1 chemokine coreceptor use among antiretroviral-experienced patients screened for a clinical trial of a CCR5 inhibitor: AIDS Clinical Trial Group A5211. Clin Infect Dis. 2007;44(4):591-595.

139. Li C, Keung A, Morrison RA, White RE. Vicriviroc, a novel CCR5 inhibitor, is not a p-glycoprotein substrate in vitro. Retrovirology. 2005;2(Suppl 1):158.

140. DeJesus E, Berger D, Markowitz M, et al. Antiviral activity, pharmacokinetics, and dose response of the HIV-1 integrase inhibitor GS-9137 (JTK-303) in treatment-naive and treatment-experienced patients. J Acquir Immune Def Syndr. 2006;43(1):1-5.

141. Matsuzaki Y, Watanabe W, Yamataka K, et al. JTK-303/GS 9137, a novel small-molecule inhibitor of HIV-1 integrase: anti-HIV activity profile and pharmacokinetics in animals. Proceedings of the 13th Conference of Retroviruses and Opportunistic Infections; 2006; Feb 5-8; Denver, CO, USA.

142. European Mode of Delivery Collaboration. Elective caesareansection versus vaginal delivery in prevention of vertical HIV-1 transmission: a randomised clinical trial. Lancet. 1999;353(9158): $1035-1039$.

143. International Perinatal HIV Group. The mode of delivery and the risk of vertical transmission of human immunodeficiency virus type 1-a meta-analysis of 15 prospective cohort studies. $N$ Engl J Med. 1999;340(13):977-987.

144. Kind C, Rudin C, Siegrist CA, et al; for the Swiss Neonatal HIV Study Group. Prevention of vertical HIV transmission: additive protective effect of elective Cesarean section and zidovudine prophylaxis. AIDS. 1998;12(2):205-210.

145. Mandelbrot L, Le CJ, Berrebi A, et al. Perinatal HIV-1 transmission: interaction between zidovudine prophylaxis and mode of delivery in the French Perinatal Cohort. JAMA. 1998;280(1): 55-60.

146. Shapiro D, Tuomala R, Pollack H, et al. Mother-to-child HIV transmission risk according to antiretroviral therapy, mode of delivery, and viral load in 2895 U.S. women (PACTG 367). Proceedings of the 11th Conference on Retroviruses and Opportunistic Infections; 2004 Feb 8-11; San Francisco, CA, USA. [abstract 99].

147. European Collaborative Study. Mother-to-child transmission of HIV infection in the era of highly active antiretroviral therapy. Clin Infect Dis. 2005;40(3):458-465.
148. Warszawski J, Tubiana R, Le Chenadec J, et al; ANRS French Perinatal Cohort. Mother-to-child HIV transmission despite antiretroviral therapy in the ANRS French Perinatal Cohort. AIDS. 2008;22(2): 289-299.

149. Marcollet A, Goffinet F, Firtion G, Pannier E, Le Bret T, Brival ML, et al. Differences in postpartum morbidity in women who are infected with the human immunodeficiency virus after elective cesarean delivery, emergency cesarean delivery, or vaginal delivery. $\mathrm{Am} J$ Obstet Gynecol. 2002;186(4):784-789.

150. Duarte G, Read JS, Gonin R, et al. Mode of delivery and postpartum morbidity in Latin Américan and Caribbean countries among women who are infected with human immunodeficiency virus-1: the NICHD International Site Development Initiative (NISDI) Perinatal Study. Am J Obstet Gynecol. 2006;195(1):215-229.

151. Committee on Obstetric Practice. ACOG Committee opinion scheduled Cesarean delivery and the prevention of vertical transmission of HIV infection. Number 234, May 2000 (replaces number 219, August 1999) Int J Gynaecol Obstet. 2001;73(3): 279-281.

152. Buchholz B, Beichert M, Marcus U, et al. German-Austrian recommendations for HIV-therapy in pregnancy and in HIV-exposed newborn - update 2005. Eur J Med Res. 2006;11(9): 359-376.

153. Stanton CK, Holtz SA. Levels and trends in Cesarean birth in the developing world. Stud Fam Plann. 2006;37(1):41-48.

154. Rousseau CM, Nduati RW, Richardson BA, et al. Association of levels of HIV-1-infected breast milk cells and risk of mother-to-child transmission. J Infect Dis. 2004;190(10):1880-1888.

155. Dabis F, Elenga N, Meda N, et al. 18-month mortality and perinatal exposure to zidovudine in West Africa. AIDS. 2001;15(6): 771-779.

156. Dabis F, Msellati P, Meda N, et al. 6-month efficacy, tolerance, and acceptability of a short regimen of oral zidovudine to reduce vertical transmission of HIV in breastfed children in Côte d'Ivoire and Burkina Faso: a double-blind placebo-controlled multicentre trial. DITRAME Study Group. DIminution de la Transmission Mére-Enfant. Lancet. 1999;353(9155):786-792.

157. Jackson JB, Musoke P, Fleming T, et al. Intrapartum and neonatal single-dose nevirapine compared with zidovudine for prevention of mother-to-child transmission of HIV-1 in Kampala, Uganda: 18-month follow-up of the HIVNET 012 randomised trial. Lancet. 2003;362(9387):859-868.

158. Thistle P, Gottesman M, Pilon R, et al. A randomized control trial of an ultra-short zidovudine regimen in the prevention of perinatal HIV transmission in rural Zimbabwe. Cent Afr J Med. 2004;50(9-10):79-84.

159. Petra Study Team. Efficacy of three short-course regimens of zidovudine and lamivudine in preventing early and late transmission of HIV-1 from mother to child in Tanzania, South Africa, and Uganda (Petra study): a randomised, double-blind, placebo-controlled trial. Lancet. 2002;359(9313):1178-1186.

160. Dabis F, Bequet L, Ekouevi DK, et al. Field efficacy of zidovudine, lamivudine and single-dose nevirapine to prevent peripartum HIV transmission. AIDS. 2005;19(3):309-318.

161. Olayinka B, Oni AO, Mbajiorgu FE. Impact of infant feeding practices on the risk of mother to child transmission of HIV-1 in Zimbabwe. J Paediatr Child Health. 2000;36(4):313-317.

162. World Health Organization/UNICEF. HIV transmission through breastfeeding: a review of the available evidence, 2004. [cited 2009 June 23]. Available from: http://www.unfpa.org/upload/lib_pub_ file/276_filename_HIV_PREV_BF_GUIDE_ENG.pdf.

163. Thior I, Lockman S, Smeaton LM, et al. Breastfeeding plus infant zidovudine prophylaxis for 6 months vs formula feeding plus infant zidovudine for 1 month to reduce mother-to-child HIV transmission in Botswana. A randomized trial: the mashi study. JAMA. 2006;296(7):794-805. 
164. Kilewo C, Karlsson K, Massawe A, et al; Mitra Study Team. Prevention of mother-to-child transmission of HIV-1 through breastfeeding by treating infants prophylactically with lamivudine in Dar es Salaam, Tanzania: the Mitra Study. J Acquir Immune Defic Syndr. 2008;48(3):315-323.

165. Thomas T, Masaba R, Ndivo R, et al. PMTCT of HIV-1 among mothers using HAART: the Kisumu Breastfeeding Study, Kisumu, Kenya 2003-2007. 15th Conference on Retroviruses and Opportunistic Infections; 2008 February 3-6; Boston, MA [abstract 45aLB]

166. Palombi L, Marazzi MC, Voetberg A, Magid NA. Treatment acceleration program and the experience of the DREAM program in prevention of mother-to-child transmission of HIV. AIDS 2007;21(Suppl 4):S65-S71.
167. Arendt V, Ndimubanzi P, Vyankandondera J, et al. AMATA study: effectiveness of antiretroviral therapy in breastfeeding mothers to prevent post-natal vertical transmission in Rwanda. Proceedings of the 4th International AIDS Society Conference on HIV Pathogenesis and Treatment; 2007 July 22-25; Sydney, Australia [abstract TUAX102].

\section{Publish your work in this journal}

HIV/AIDS - Research and Palliative Care is an international, peerreviewed open-access journal focusing on advances in research in HIV, its clinical progression and management options including antiviral treatment, palliative care and public healthcare policies to contro viral spread. The journal welcomes original research, basic science, clinical \& epidemiological studies, reviews \& evaluations, expert opinion \& commentary, case reports \& extended reports. The manuscript management system is completely online and includes a very quick and fair peer-review system. Visit http://www.dovepress.com/ testimonials.php to read real quotes from published authors.

Submit your manuscript here: http://www.dovepress.com/hivaids---research-and-palliative-care-journal 